\title{
On the Relationship between Translation Competence and Higher-order Thinking Skills of Novice Translators
}

\author{
By Hamed Ghaemi* \& Seyedhamed Sadoughvanini ${ }^{\dagger}$
}

\begin{abstract}
Higher-order thinking, known as higher order thinking skills (HOTS), is a notion of education improvement based on Bloom's taxonomy. The belief is that some types of learning involve more cognitive processing than others, but also have more generalized profits. The present study aims at investigating the relationship between translation competence along with its components and higher-order thinking skills of novice translators. To this end, 37 students of translation studies studying at the $5^{\text {th }}$ semester were selected. The rationale behind this was that the students of the fifth semester don't have any solid understanding and experience of translation so they are considered as novice translator. Having collected the data from two questionnaires of Translation Competence Acquisition Questionnaire and Higher-order Thinking Skills, a correlational analysis was conducted. The results of Spearman's rank order correlation revealed a strong correlation $(\rho=0.786)$ showing not only does Translation Competence have statistically significant relationship with higherorder thinking skills in general, but also their components and sub-competences reveal strong and meaningful relationship.
\end{abstract}

Keywords: Translation competence, Higher-order thinking skills, translation notion, translation errors, translation problems

\section{Introduction}

\section{Higher Order Thinking Skills}

Higher-order thinking is considered the 'top end' of Bloom's (or any other) taxonomy: analyze, evaluate, and Create, or, in the older language, Analysis, Synthesis, and Evaluation (Brookhart, 2010). More specifically, it is a mixture of usually digital tools and resources selected by the learner to support different aspects of the learning process, ranging from goal setting to selecting materials and assessment as the final point (Reinders 2014: 14).

Establishing "higher-order-thinking skills" in students is considered an important educational goal. The focus and emphasis of this new approach to learning is on students' abilities and interests. In this way, the responsibility of learning activities outside the learning environment is directly placed on the students. This approach relies on more attractive learning resources including videos, audios, online readings and learning websites. Then, teachers' creativity plays an important role in employing the required skills to design an interactive environment leading to interactive and collaborative work of students. Pair work

*Faculty Staff, Bahar Institute of Higher Education, Mashhad, Iran.

${ }^{\dagger}$ Bahar Institute of Higher Education, Mashhad, Iran. 
and group work are among the interactive activities which can be promoted by teachers. Teachers should prepare hands-on activities. Higher-order-Thinking Skills paves the way for the acquisition of knowledge and assists its transformation into responsible actions regardless of students' future role in society. Students are encouraged to apply critical thinking for the analysis of unfamiliar situations. Therefore, their problem-solving skills, asking-questions abilities, and decisionmaking skills will be framed by rational thinking. Higher-order Thinking Skills (HOTS) is a popular concept in American education. It distinguishes critical thinking skills from low-order learning outcomes, such as those attained by rote memorization. HOTS include synthesizing, analyzing, reasoning, comprehending, application, and evaluation. HOTS is based on various taxonomies of learning, particularly the one developed by Benjamin Bloom (1956) in his book titled 'Taxonomy of Educational Objectives: The Classification of Educational Goals'. Higher-order thinking skills are reflected by the top three levels in Bloom's Taxonomy: analysis, synthesis, and evaluation.

\section{Bloom's Taxonomy and HOTS}

Bloom's taxonomy is a popular concept taught in the majority of American teacher-education programs. As such, it may be among the most well-known educational theories pertaining to teachers nationally. As the Curriculum \& Leadership Journal notes:

"While Bloom's Taxonomy is not the only framework for teaching thinking, it is the most widely used, and subsequent frameworks tend to be closely linked to Bloom's work.... Bloom's aim was to promote higher forms of thinking in education, such as analyzing and evaluating, rather than just teaching students to remember facts (rote learning)."

Bloom's taxonomy contains six levels to promote higher-order thinking. The six levels are: knowledge, comprehension, application, analysis, synthesis, and evaluation. (The taxonomy's levels were later revised as remembering, understanding, applying, analyzing, revising, and creating.) The Lower-Order Thinking Skills (LOTS) involve a sheer memorization while higher-order thinking focuses on understanding and applying that knowledge.

The top three levels of Bloom's taxonomy-which is often displayed as a pyramid, with ascending levels of thinking at the top of the structure - are analysis, synthesis, and evaluation. These levels of the taxonomy all involve critical or higher-order thinking. Accordingly, students with higher thinking abilities can apply the knowledge and skills they have obtained to new contexts. Each level of this taxonomy displays and reveals how higher-order thinking is applied in education.

\section{Why Higher Order Thinking Leads to Effective Study}

A large number of students have reported that a huge portion of instructions at high school was about remembering and understanding big amounts of content 
and then demonstrating this comprehension periodically on tests and exams. Bloom's Taxonomy is a framework which begins with these two levels of thinking as the launch pad of our brains to five other higher order levels of thinkinghelping students move beyond remembering and recalling information towards a deeper application, analysis, synthesis, evaluation, and creation-the levels of thinking that teachers and lecturers have in mind while designing exams and paper assignments. Because it is in these higher levels of thinking that effective and deep learning of information takes place in brains, it's crucial for teachers to help students incorporate and integrate higher order thinking into their studying habits.

The following levels of Bloom's taxonomy can help you assess your comprehension of readings, lecture notes, and other course materials. By making and answering questions from a variety of categories, students can achieve a better preparation for all types of exam questions. While studying, students can start by asking questions from the level of remembering. Then, they can gradually and progressively move through the levels to push to obtain a deeper understanding leading to a more meaningful study followed by improving longterm retention.

\section{Level 1: Remember}

This level helps us recall foundational or factual information: names, dates, formulas, definitions, components, or methods.

\section{Level 2: Understand}

Understanding means that we can explain main ideas and concepts and make meaning by interpreting, classifying, summarizing, inferring, comparing, and explaining.

\section{Level 3: Apply}

Application allows us to recognize or use concepts in real-world situations and to address when, where, or how to employ methods and ideas.

\section{Level 4: Analyze}

Analysis means breaking a topic or idea into components or examining a subject from different perspectives. It helps us see how the "whole" is created from the "parts." It's easy to miss the big picture by getting stuck at a lower level of thinking and simply remembering individual facts without seeing how they are connected. Analysis helps reveal the connections between facts.

\section{Level 5: Synthesize}

Synthesizing means considering individual elements together for the purpose of drawing conclusions, identifying themes, or determining common elements. Here you want to shift from "parts" to "whole."

\section{Level 6: Evaluate}

Evaluating means making judgments about something based on criteria and standards. This requires checking and critiquing an argument or concept to form an opinion about its value. Often there is not a clear or correct answer to this type of question. Rather, it's about making a judgment and supporting it with reasons and evidence. 


\section{Level 7: Create}

Creating involves putting elements together to form a coherent or functional whole. Creating includes reorganizing elements into a new pattern or structure through planning. This is the highest and most advanced level of Bloom's Taxonomy.

\section{Translation Competence}

Over the recent years, translation and interpretation studies have attracted a great deal of attention; this appears to be affected by the temporal and special needs and demands of academic and industrial circles. The advances and developments in science and technology and the need to exchange the newlydeveloped information, knowledge and technology in native speakers' countries highlight a growing demand to train professional translators.

One of the requirements of training professional translators is to look more deeply into the translation professionalism. One of the most critical factors contributing to professionalism in translation is the development of translation competence, which has been called differently by different scholars, as Transfer Competence (Nord 1992), Translational Competence (Toury 1995), Translation Performance (Wilss 1989), and even Translation Skill (Lowe 1987). Borsch (1986), Gerloff (1987), Seguinot (1991) and Lorscher (1991) examined translation competence acquisition. However, it appears more qualitative, quantitative and empirical studies are needed to determine what kinds of factors can affect it. Some researchers, i.e., Ressurreccio, Piorno, and Izquierdo (2008) investigated the impact of textual genre on translation competence acquisition (TCA). However, the role of other factors, such as translation training courses and translation tasks, has remained unclear. PACTE group, i.e. Process of Acquisition of Translation Competence and Evaluation, (2000) presents the translation competence model that is the basis for designing the hypotheses of an empirical-experimental study of translation competence. Their research is the first stage in a larger project to investigate the process of translation competence acquisition. They describe the theoretical framework and the first models that were designed in 1998; along with the modification introduced in 1998 the translation competence model was developed as a result of the first exploratory studies.

\section{PACTE Group Model}

The PACTE model of Translation competence focuses on both the theoretical aspect of translation and its procedural aspects. PACTE (2000) defined TC as "the underlying system of knowledge and skills needed to be able to translate" (Orozco 2002: 5). PACTE`s model includes a set of interrelated sub-competencies, and mostly stresses procedural aspects of translation (PACTE 2003: 23).

According to this group, TCA is a restructuring of competences. These competences, in the beginning, looked like this (Orozco 2000): 
Figure 1. PACTE`s Model of TC

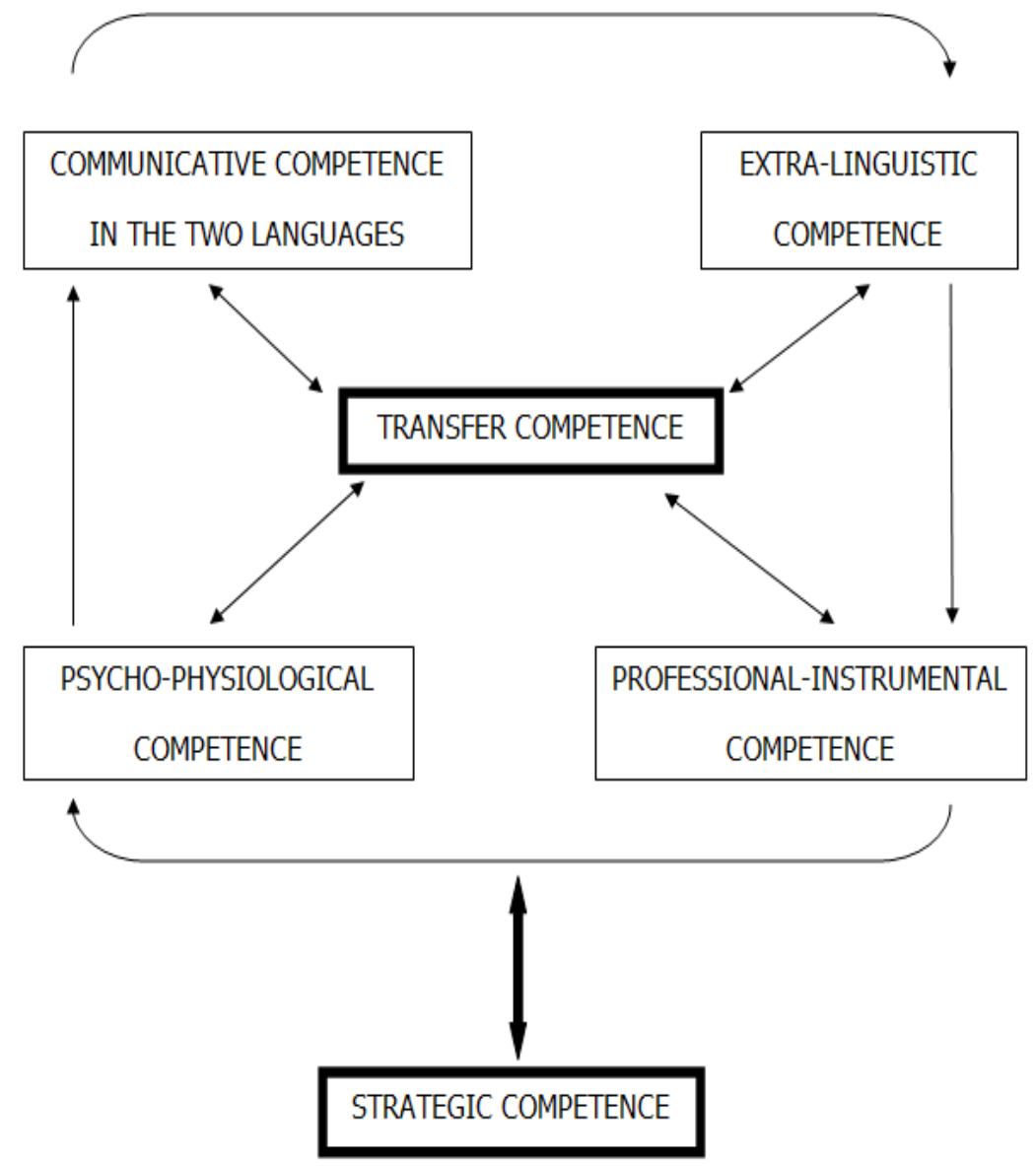

The competences were defined as follows:

1. Transfer competence: the ability to finish the process of translation, considering the functions of receptor.

2. Communicative competence: the ability to understand the source language and produce the target language.

3. Extra-linguistic competence: peripheral knowledge about translation such as bicultural and subject knowledge.

4. Instrumental-professional competence: knowledge of translation tools and profession.

5. Psycho-physiological competence: the ability to draw upon the cognitive and psychomotor resources.

6. Strategic competence: the ability to solve the problems faced with while translating (PACTE 2000: 48).

The previous models were merely theoretical, so PACTE group created several tools to validate their model empirically. They measure translation problems, 
translation errors and translators' notion about translation in their research on TC. Over time, the results of validation caused the PACTE group to modify their model and the model further developed into the following construct (PACTE 2005):

Figure 2. PACTE`s Model of TC

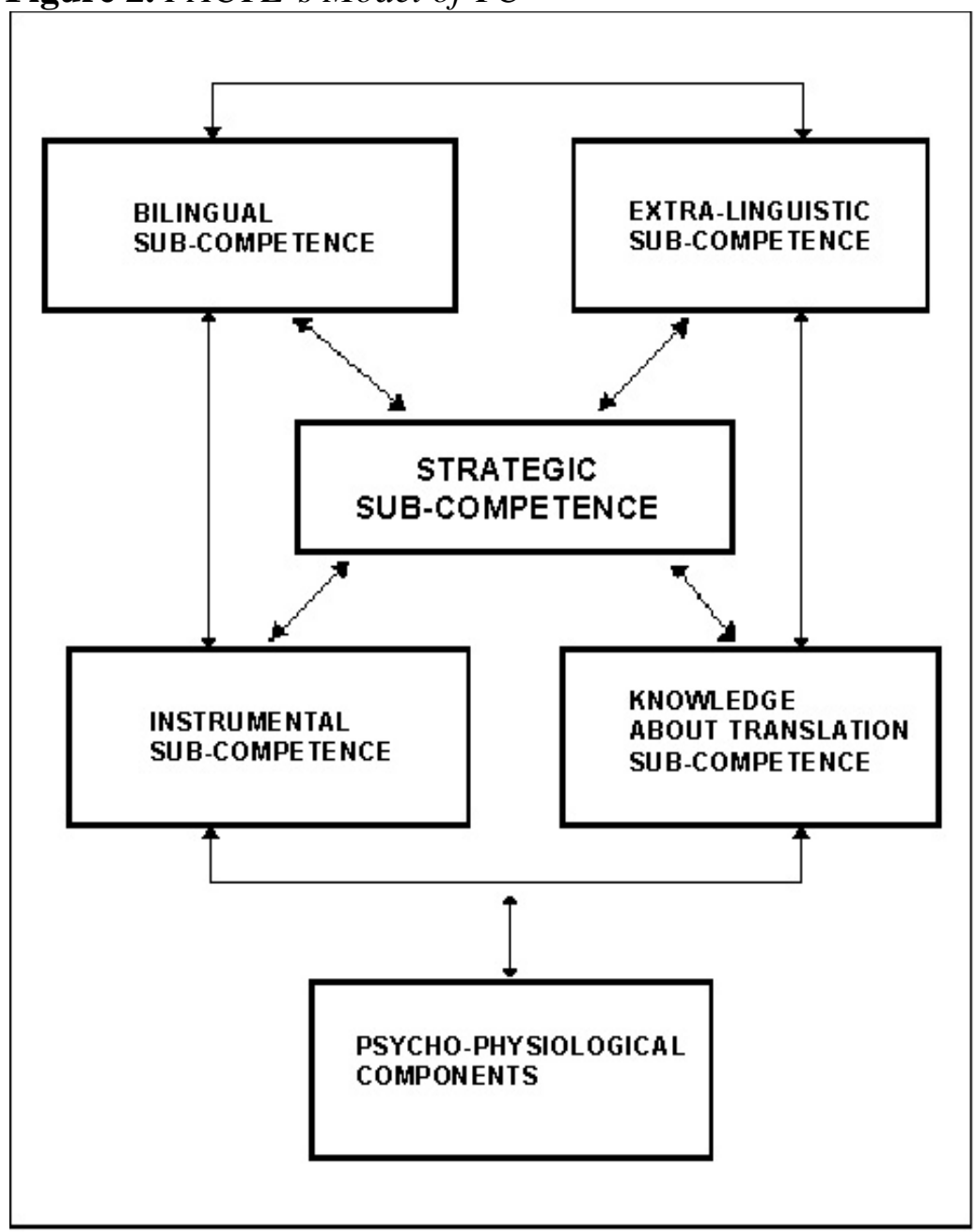

The model comprised the following competences (PACTE 2003):

1. "Bilingual sub-competence: which is mostly procedural knowledge for communicating in two languages. It consists of pragmatic, socio-linguistic, textual, grammatical and lexical knowledge in the two languages.

2. Extra-linguistic sub-competence: is declarative knowledge, involving bicultural, encyclopaedic and subject knowledge.

3. Knowledge about translation sub-competence: which is declarative knowledge mainly about the translation profession.

4. Instrumental sub-competence: which is procedural knowledge about the use of documentation resources and IT equipment in translation. Also, it focuses on the use of different dictionaries, encyclopaedias and electronic 
corpora.

5. Strategic sub-competence: which is procedural knowledge used to control the translation process.

6. Psycho-physiological components: different mechanisms such as cognitive and attitudinal components are included in this competence, (PACTE 2003).

PACTE came to the conclusion that TC is composed of several subcompetences with strategic competence in a central position (PACTE 2000). Both models presented by Campbell (1991) and PACTE (2003) are important, because they consider psycho- physiological characteristics in their models.

After the translation competence model has been established, Orozco and Hurtado (2002) tried to design and develop the instruments which could accurately measure it. Orozco and Hurtado (2002) developed the instruments for measuring the process of acquiring translation competence in written translation. Translation competence and its process of acquisition were described, and then three measuring instruments. In 2013, Alavi and Ghaemi developed, validated and assessed the reliability of Translation Competence Acquisition Questionnaire. (Alavi and Ghaemi 2013).

According to Alavi and Ghaemi (2013) three measuring instruments can be used to evaluate the Translation Competence. The first one is called "Translation Notions Instrument" (TNI), the second one is "Translation Problems Instrument" (TPI) and the last instrument is "Translation Errors Instrument" (TEI). To measure TC, it is essential to define what makes TC and how it can be acquired. The dynamic model presented by PACTE considers TC to have six subcompetences (PACTE 1998, 2000):

1. Communicative competence in both languages.

2. Extra-linguistic competence.

3. Transfer competence.

4. Instrumental competence.

5. Psychophysiological competence.

6. Strategic competence (PACTE 1998, 2000: 72).

Orozco (2001) has identified three characteristics that are shared by all the indicators of translation competence acquisition. First, all the translation competence acquisition indicators should affect the whole process of translation, not just some of its stages. Second, they should be observable and measurable. Finally, all of them should give an indirect view of translation strategies, which is not directly observed but is essential to translation competence (Orozco, 2001). Orozco and Hurtado (2002) have chosen three indicators to make translation competence acquisition operational. These indicators are as follows.

1. Behavior when encountered with a translation problem

2. Behavior related to translation errors

3. General Notions about translation 
The definitions on which the three instruments of measuring translation competence acquisition are developed are as follow:

According to Nord (1992: 7), a translation problem "is an objective problem which every translator has to solve during a particular translation task". Orozco (2001) believes that all translation problems share three features. First of all, they should exist at any stage of translation process. Second, it should be observable, and lastly students should have the ability to use translation strategies to solve their problems (Orozco 2001).

Nord (1997) states that the source of a translation error is a translation problem, which has not been solved or has been solved inappropriately. As can be seen, this element also shares the same three qualities as translation problems, that is, it can be observed, it can happen at any stage of translation, and it is indicator of a student's use of translation strategies.

At last, general notions about translation depict the students' process of translation, because it depends on the students' attitudes towards translation, and shows that they have an aim for a particular translation task (Orozco 2001).

Nord (1997) puts out that the lack of knowledge of translation notions causes translation errors. Thus, translation notions also share the same three qualities mentioned above.

Overall, three instruments, which have been developed by Orozco (2001), to assess the Translation Competence Acquisition, are as follows:

1. Translation Notions Instruments

2. Translation problems Instruments

3 Translation Errors Instruments.

More details on the components of each instrument are discussed in the following section.

\section{Translation Notion Instrument}

Translation Notion Instrument (TNI) questionnaire, developed by Orozco and Hurtado (2002), consists of 12 items and is divided into three categories of Multiple Choice, True/False, and Open-Items. TNI is a questionnaire which covers seven factors within the "abstract" notion of translation (Orozco and Hurtado 2002). Seven factors like notions about translation, notions about translation problems, the translation units, translation equivalence, translation functions, translation competence and translation strategies are included in the questionnaire (Orozco 2000).

\section{Translation Problems Instrument}

Translation Problems Instrument (TPI) questionnaire, developed by Orozco and Hurtado (2002), consists of two parts. The first part includes a task through which students should translate a text and the second task is a TPI questionnaire. In the text students are supposed to translate four translation problems, namely: 
pragmatic, extra-linguistic, transfer and linguistic. Orozco and Hurtado (2002) maintained that these four types of translation problems are chosen because in order to solve them the translator needs to draw upon all the components of translation competence (Orozco and Hurtado 2002). After students translated the text, they are asked to answer the TPI questionnaire. The evaluator reads the translated text along with the TPI questionnaire to see whether each student was able to solve the translation problem.

\section{Translation Errors Instrument}

Translation Errors Instrument (TEI) is divided into two sections. The first section overlaps with the first part of TPI, i.e. translation of a text (Orozco and Hurtado 2002). The second section is the correction of the translation to see how many errors there are of each type.

\section{Research Questions}

The current study tried to find reasonable answers to the following questions:

1. Is there any statistically significant relationship between Translation Competence and Higher-Order thinking skills of novice translators?

2. Is there any statistically significant relationship between Translation Notions and Analyzing skills of novice translators?

3. Is there any statistically significant relationship between Translation Notions and Evaluating skills of novice translators?

4. Is there any statistically significant relationship between Translation Notions and Creating skills of novice translators?

5. Is there any statistically significant relationship between Translation Problems and Analyzing skills of novice translators?

6. Is there any statistically significant relationship between Translation Problems and Evaluating skills of novice translators?

7. Is there any statistically significant relationship between Translation Problems and Creating skills of novice translators?

8. Is there any statistically significant relationship between Translation Errors and Analyzing skills of novice translators?

9. Is there any statistically significant relationship between Translation Errors and Evaluating skills of novice translators?

10. Is there any statistically significant relationship between Translation Errors and Creating skills of novice translators? 


\section{Methods}

\section{Participants}

Participants were selected from B.A. students of English Translation Studies at Bahar Institute of Higher Education in Mashhad, Iran. Since the participants should not have any academic translation training experience, only students who were studying in the fifth semester were selected. According to Iran's curriculum of Translation Studies, the students should are supposed to study only General English in the first 4 semesters and they actually enter the $5^{\text {th }}$ semester, when they ought to start translating in practice, without any background in translation. The age range of participants was between 19 and 22 years old and based on the prior completion of the courses, they were all in the $5^{\text {th }}$ semester, studying Translation Studies.

\section{Instruments}

For the purpose of this study two questionnaires were employed. First, a Higher-order thinking skills questionnaire used including 30 questions divided into three levels based on Bloom's Taxonomy. It was analyzing (15 questions), evaluating (10 questions) and creating (5 questions). These questions were multiple choice. Each question scored one grade for a correct answer and zero for the wrong answer with a total score of 30 points. The reliability of the tool was confirmed by Cronbach's Alpha test $r=0.89$. The second instrument of the present study was Translation Competence Acquisition Questionnaire (TCAQ) developed by Alavi and Ghaemi (2013). The reported reliability index is .807. TCAQ includes three sub-instruments as follows:

1 Translation Error Instrument (TEI)

2 Translation Problem Instrument (TPI)

3 Translation Notions Instrument (TNI)

\section{Translation Notions Instrument (TNI)}

TNI is a multidimensional questionnaire as it covers seven factors within the "abstract" notion of what translation is (Orozco and Hurtado 2002). Seven factors like notions about translation, notions about translation problems, the translation units, translation equivalence, translation functions, translation competence and translation strategies are included in the questionnaire (Orozco 2000). Based on the findings of Orozco and Hurtado (2002), this questionnaire measures two main constructs of Knowledge about translation, as measured by items 1, 2, 3, 4, 5, 6, 7, 12, 13, and 14, of the TC questionnaire and Strategic sub-competence, which is measured by items $15,16,17,40,50,51,52,53,54$, 55 , and 56. 


\section{Translation Problems Instrument (TPI)}

TPI questionnaire consists of two parts. The first part includes a task translating a general text from English to Persian and the second one a TPI questionnaire. In the text students are supposed to translate four translation problems, namely: pragmatic, extra-linguistic, transfer and linguistic. Orozco and Hurtado (2002) maintained that these four types of translation problems are chosen based on the rationale that in order to solve them the translator needs to mobilize all the components of translation competence (Orozco and Hurtado 2002). After students translated the text, they were asked to answer the TPI questionnaire.

The evaluator read the translated text together with the TPI questionnaire. Therefore, the translation of each student was checked to see whether each problem had been solved or not. This questionnaire measures two main constructs of Bilingualism and Instrument sub-competences. Bilingual sub- competence was measured through items $21,22,23,24,29,30,31,32,33,34,35,36,37,38,39$, 43,44 , and 45 . Also, Instrumental sub-competence was measured through items 8 , $9,10,11,18,19,20,28,41$, and 42 of TC questionnaire.

\section{Translation Error Instrument (TEI)}

TEI was aimed to measure two constructs of Extra-linguistics and Psychophysiological components. The former was measured through items 25, 26, 44, 49, 56, and 57 and the latter through items 27, 46, 54, 55 and 57.

\section{Procedure}

As the main aim of the present study was to assess the relationship between translation competence and higher-order thinking skills of novice translators, only were the students of the fifth semester selected, hence the intact group design was chosen for the purpose of this study.

A group of 37 translation studies students was selected and they were given the Translation Competence Acquisition Questionnaire. in view of the fact that TCAQ takes a long time to be completed, the participants were asked to take the questionnaire home and complete and return it to the researchers within a week. Having returned the questionnaire, the participants were asked to gather in the conference hall of Bahar institute of higher education to answer the Higher-order thinking skills questionnaire. This instrument took an hour to be completed. The data collected from both instruments were used for the purpose of data analysis.

\section{Data Analysis}

To carry out the analysis and due to the nature of the collected data, Spearman Rank Order Correlation was used. The present study aimed at exploring the 
various aspects of the relationship between higher order thinking and translation competence. To answer the first research question of this study and investigate the extent of the relationship between the participants' translation competence and high order thinking, Spearman's rank order correlation was conducted. The results revealed a strong correlation $(\rho=0.786)$ showing the students with higher thinking order possess a higher level of translation competence.

High order thinking had three subcomponents of analysis, evaluation and creation. Likewise, translation competence had three subcomponents of translation notion, translation problem, and translation error. Hence, analyzing the one-one relationship of these subcomponents can be illustrative.

In the first phase, Spearman's rank order correlation was conducted to find the extent of the relationship of translation notion to analyzing, evaluating and creating skills answering research questions 2,3 , and 4 . According to the results, translation notion revealed a strong relationship to analyzing $(\rho=0$. 801), evaluating ( $\rho=$ $0.754)$, and creating $(\rho=0.813)$.

In the second phase, Spearman's rank order correlation was conducted to find the extent of the relationship of translation problem to analyzing, evaluating and creating skills answering research questions 5, 6, and 7. According to the results, translation problems revealed a strong relationship to analyzing $(\rho=0.823)$, evaluating $(\rho=0.817)$, and creating $(\rho=0.845)$.

In the third phase, Spearman's rank order correlation was conducted to find the extent of the relationship of translation errors to analyzing, evaluating and creating skills answering research questions 8,9 , and 10. According to the results, translation errors revealed a strong relationship to analyzing $(\rho=0.789)$, evaluating $(\rho=0.812)$, and creating $(\rho=0.822)$.

It is worth noting that each sub-component of translation competence consists of two other subcomponents. Translation notion constitutes knowledge about translation and strategic subcomponents. Translation problem includes bilingualism and instrument. For Translation error, extralinguistic and psychophysiological are the two subcomponents. Investigating the relationship of each of the six subcomponents to all of the three subcomponents of high order thinking demonstrates detailed aspects of the relationship between translation competence's subcomponents and HOTS' subcomponents. Therefore, three more phases of correlational analysis are needed.

In the fourth phase, Spearman's rank order correlation was conducted to find the extent of the relationship of translation notion's subcomponents to analyzing, evaluating and creating skills. According to the results, knowledge about translation revealed a strong relationship to analyzing $(\rho=0.723)$, evaluating $(\rho=0.717)$, and creating $(\rho=0.742)$. Similarly, a strong relationship of strategic sub-component to analyzing $(\rho=0.893)$, evaluating $(\rho=0.887)$, and creating $(\rho=0.865)$ was discovered.

In the fifth phase, Spearman's rank order correlation was conducted to find the extent of the relationship of translation problem's subcomponents to analyzing, evaluating and creating skills. According to the results, bilingualism revealed a strong relationship to analyzing $(\rho=0.869)$, evaluating $(\rho=0.857)$, and creating 
( $\rho=0.863)$. Similarly, a strong relationship of instrument to analyzing $(\rho=0.839)$, evaluating $(\rho=0.889)$, and creating $(\rho=0.850)$ was discovered.

In the sixth phase, Spearman's rank order correlation was conducted to find the extent of the relationship of translation error's subcomponents to analyzing, evaluating and creating skills. According to the results, extralinguistic revealed a strong relationship to analyzing $(\rho=0.899)$, evaluating $(\rho=0.897)$, and creating $(\rho=0.884)$. Similarly, a strong relationship of psychophysiological to analyzing ( $\rho=0.856)$, evaluating $(\rho=0.869)$, and creating $(\rho=0.895)$ was discovered.

\section{Discussion and Conclusion}

Higher-order thinking, known as higher order thinking skills (HOTS), is a notion of education improvement based on Bloom's taxonomy. The belief is that some types of learning involve more cognitive processing than others, but also have more generalized profits. In Bloom's taxonomy, skills concerning analysis, evaluation and creation are thought to be of a higher order than the learning of facts and concepts which needs diverse learning and teaching methods. Higherorder thinking includes the learning of multipart critical skills such as critical thinking and problem solving. Higher-order thinking is harder to learn or teach but also more respected because such skills are more likely to be practical in novel situations (i.e., situations other than those in which the skill was learned).

As the data analysis of the study reveals, there was a statistically significant relationship between Translation Competence Acquisition and Higher-order thinking skills of novice translators. This suggests that all the subcomponents of higher-order thinking skills including analyzing, creating and evaluating considerably assist the translator to enhance their translation competence and performance. Moreover, a deep analysis of both questionnaires' subcomponents showed more interesting findings. Bilingual sub-competence, which is one of the components of translation problems, consists of procedural knowledge needed to communicate in two languages including pragmatic, sociolinguistic, grammatical, lexical knowledge, etc. Pragmatic knowledge, as an example, is "how individuals communicate meaning and how they produce contextually appropriate utterances, sentences, or texts. Instrumental sub-competence, as another sub-component of Translation problem, refers to procedural knowledge related to the use of dictionaries of all kinds, encyclopedias, electronic corpora, etc. The results of analysis showed that there was a significant relationship between translation problems and all three components of higher-order thinking skills, meaning analyzing, which help us see how the "whole" is created from the "parts", evaluating, requiring checking and critiquing an argument or concept to form an opinion about its value, and creating, involving putting elements together to form a coherent or functional whole as well as reorganizing elements into a new pattern or structure through planning, play a crucial role in developing translation competence of novice translators.

Extra-linguistic knowledge, including world knowledge, domain-specific knowledge, bicultural knowledge, etc., is a sub-component of translation error. 
The results revealed that translation errors had meaningful correlation with all three subcomponents of Higher-Order thinking skills. This signifies that the "Analysis" category in Bloom's taxonomy which involves breaking information down into parts and different forms, and drawing comparisons between a text and background knowledge data improves the extra-linguistic knowledge, i.e. translation errors, of translators to a great extent. Also, creating, as another category of Higher-order thinking skills, involves linking new information with prior knowledge or with multiple texts to develop a new idea, establish a new way of thinking, or create a new product of some type. This is exactly why the extralinguistics component of Translation Errors has a strong relationship with HOTS. Psycho-physiological components of translation errors involves thinking critically, intellectual inquisitiveness, and cognitive components. The findings of this study confirm that the development of Psycho-physiological components is highly dependent upon the translator's creating, evaluating and analyzing skills.

Strategic sub-competence, as a component of translation notion, has also a strong relationship with all the three skills of HOTS. According to this subcompetence, translators should, firstly, plan the translation process, identify translation problems, apply the procedures to solve them, and then proceed to perform the translation task. Analyzing skills of HOTS involve students' use their own judgment to begin analyzing the knowledge they have acquired. At this point, they begin understanding the underlying structure of knowledge and also are able to distinguish between fact and opinion. What's more, evaluation, the top level of Bloom's taxonomy, involves students making judgments about the value of ideas, items, and materials. Evaluation is the top level of Bloom's taxonomy pyramid because it is at this level that students are expected to mentally assemble all they have learned to make informed and sound evaluations of the material. These descriptions show why Strategic sub-competence had statistically significant relationship with all three main skills of HOTS.

\section{References}

Alavi SM, Ghaemi H (2013) Reliability assessment and construct validation of translation competence questionnaire (TCQ) in Iran. Language Testing in Asia 3(1): 18.

Brookhart SM (2010) How to Assess Higher-Order Thinking Skills in Your Classroom. Alexandria, VA: ASCD.

Bloom BS (1956) Taxonomy of Educational Objectives, Handbook the Cognitive Domain. New York: David McKay.

Borsch S (1986) Introspective methods in research in interlingual and intercultural communication. In Discourse and cognition in translation and second language acquisition studies, House J, Blum-Kulka S. Tubingen (eds).

Campbell S (1991) Towards a model of translation competence. Meta: Translator's Journal 36 (2-3): 329-343.

Gerloff P (1987) Identifying the Unit of Analysis in Translation: some uses of ThinkAloudProtocol data. In Introspection in Second Language Research, C Faerch, G Kasper (eds), 135-158. Clevedon: Multilingual Matters.

Lörscher W (1991) Translation Performance, Translation Process, and Translation Strategies.Tübingen: Narr. 
Lowe P (1987) Revising the ACTFL/ETS Scales for a New Purpose: Rating Skill in Translating. In Translation Excellence: Assessment, Achievement, Maintenance. AmericanTranslators Association Series, MG Rose (ed), vol. 1, 53-61. New York: SUNY Binghamton Press.

Montalt Ressurreccio V, Ezpeleta Piorno P, Garcia Izquierdo I (2008) The acquisition of translation competence through textual genre. Translation Journal 12(4): 2-12.

Nord CH (1992) Text analysis in translator training. In Teaching Translation and Interpreting, C Dollerup and A Loddegaard (eds), 39-48. Amsterdam-Philadelphia: John Benjamins.

Nord C (1997) Translating as a purposeful activity. Functionalist Approaches Explained. Manchester: St. Jerome Publishing.

Orozco M (2000) Instrumentos de medida de la adquisición de la competencia traductora:construcción y validación. Unpublished Doctoral Thesis. Departament de Traducció id'Interpretació, Universitat Autònoma de Barcelona.

Orozco M (2001) Revisión de investigaciones empíricas en traducción escrita [Review of empirical research in written translation]. Barcelona: Gedisa.

Orozco M, Hurtado A (2002) Measuring translation competence acquisition. Meta: Translator's Journal 47(3): 375-402.

PACTE (2000) Acquiring Translation Competence: Hypotheses and Methodological Problems ofa Research Project. In Investigating Translation, A Beeby, D Ensinger, M Presas (eds). Amsterdam/Philadelphia: John Benjamins.

PACTE (2003) Building a Translation Competence Model. In Triangulating Translation: Perspectives in Process Oriented Research, F Alves (ed), 43-66. Amsterdam: John Benjamins.

PACTE (2005) Investigating translation competence: Conceptual and methodological issues. Meta: Translator's Journal 50(2): 609-619.

Reinders H (2014) Touch and gesture-based language learning. Some possible avenues for research and classroom practice. Teaching English with Technology Journal 14(1): 3-8.

Séguinot C (1991) A Study of Student Translation Strategies. In Empirical Research in Translation and Intercultural Studies, S Tirkkonen-Condit (ed.).Tübingen: Gunter Narr.

Toury G (1995) Descriptive Translation Studies and Beyond. Amsterdam/Philadelphia: JohnBenjamins.

Wilss W (1989) Towards a Multi-facet Concept of Translation Behavior. Target 34, 129149. 
